\title{
Barriers and facilitators to implementing continuous quality improvement programs in colonoscopy services: a mixed methods systematic review
}

Authors

Institutions
Bernard Candas ${ }^{1,2}$, Gilles Jobin ${ }^{3,4}$, Catherine Dubé ${ }^{5}$, Mario Tousignant ${ }^{6}$, Anis Ben Abdeljelii ${ }^{6}$, Sonya Grenier ${ }^{6}$, Marie-Pierre Gagnon ${ }^{7,8}$

Institutions are listed at the end of article.

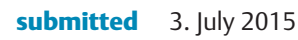
accepted after revision 5. October 2015

\section{Bibliography}

Dol http://dx.doi.org/

10.1055/s-0041-107901

Published online: 15.12 .2015

Endoscopy International Open 2016; 04: E118-E133

(c) Georg Thieme Verlag KG

Stuttgart · New York

E-ISSN 2196-9736

\section{Corresponding author}

Marie-Pierre Gagnon, PhD

Faculty of Nursing Science

Université Laval

1050 avenue de la Médecine

room 1426

Quebec City

Quebec G1V 0A6

Canada

Fax: +1-418-525-4194

marie-pierre.gagnon@fsi.ulaval. ca

\section{License terms}

\section{() (1) $\Theta \circledast$}

Background and aim: Continuous quality improvement (CQI) programs may result in quality of care and outcome improvement. However, the implementation of such programs has proven to be very challenging. This mixed methods systematic review identifies barriers and facilitators pertaining to the implementation of CQI programs in colonoscopy services and how they relate to endoscopists, nurses, managers, and patients.

Methods: We developed a search strategy adapted to 15 databases. Studies had to report on the implementation of a CQI intervention and identified barriers or facilitators relating to any of the four groups of actors directly concerned by the provision of colonoscopies. The quality of the selected studies was assessed and findings were extracted, categorized, and synthesized using a generic extraction grid customized through an iterative process.

\section{Introduction \\ $\nabla$}

With the advent of organized colorectal cancer screening in most industrialized countries, the quality of colonoscopy is increasingly becoming a focus of attention [1-4]. High quality colonoscopy services will be essential to reduce colorectal cancer (CRC) mortality, and several expert groups have stressed the importance of prioritizing the implementation of colonoscopy continuous quality improvement (CQI) programs in organized screening $[5,6]$. The organizational, clinical, and performance dimensions of colonoscopy quality have been addressed regularly [7-15]. They aim at ensuring timely access, appropriate information for and preparation of patients, adequate endoscopists' and nurses' skills as well as patient satisfaction [11-15]. Beyond general knowledge about the adoption of innovations in healthcare, the barriers and facilitators pertaining to the im-
Results: We extracted 99 findings from the 15 selected publications. Although involving all actors is the most cited factor, the literature mainly focuses on the facilitators and barriers associated with the endoscopists' perspective. The most reported facilitators to CQI implementation are perception of feasibility, adoption of a formative approach, training and education, confidentiality, and assessing a limited number of quality indicators. Receptive attitudes, a sense of ownership and perceptions of positive impacts also facilitate the implementation. Finally, an organizational environment conducive to quality improvement has to be inclusive of all user groups, explicitly supportive, and provide appropriate resources.

Conclusion: Our findings corroborate the current models of adoption of innovations. However, a significant knowledge gap remains with respect to barriers and facilitators pertaining to nurses, patients, and managers.

plementation of CQI in colonoscopy units have not been addressed yet in a systematic review.

The successful application of CQI approaches in healthcare results from the interaction of leadership, organizational culture, and teamwork to create a culture of excellence $[16,17]$. As a result of the complex nature of healthcare organizations, the implementation of innovative approaches in clinical settings depends on many factors that are both external and internal to the organization $[18,19]$. Nevertheless, some inner characteristics of organizations are more prone to facilitate this process. Customer focus, systems thinking, learning from measurement, and teamwork, as well as communication and feedback are critical in creating motivation and empowerment among users involved in CQI processes. With respect to colonoscopy, the successful implementation of a CQI program will thus depend on the involvement of physicians, nurses, and managers [20-23]. However, as a focus on customer needs 


\begin{tabular}{|c|c|}
\hline \#12 Search & (\#4 AND \#9) OR (\#3 AND \#10) OR \#11 \\
\hline \#11 Search & Colonoscopy/standards[mh] \\
\hline \#10 Search & $\begin{array}{l}\text { Endoscopy/standards[mh:noexp] OR Endoscopy, Di- } \\
\text { gestive System/standards[mh:noexp] OR Endoscopy, } \\
\text { Gastrointestinal/standards[mh:noexp] }\end{array}$ \\
\hline \#9 Search & \#5 OR \#6 OR \#7 OR \#8 \\
\hline \#8 Search & $\begin{array}{l}\text { Patient participation[mh] OR Consumer participation } \\
\text { [mh] OR Consumer advocacy[mh] OR Patient advocacy } \\
\text { [mh] OR Consumer organizations[mh] OR patient par- } \\
\text { ticipation* [tiab] OR Consumer participation [tiab] OR } \\
\text { patient involvement* [tiab] OR consumer involvement* } \\
\text { [tiab] OR consumer advocac* [tiab] OR patient advocac* } \\
\text { [tiab] OR Public participation[tiab] OR public involve- } \\
\text { ment* [tiab] OR public advocacy* [tiab] OR Consumer } \\
\text { organizations* [tiab] OR ((Patient }^{*}[\text { ti] OR Public[ti] OR } \\
\text { Consumer[ti]) AND (Participation* [ti] OR Involvement } \\
\text { [ti] OR Advocac* [ti] OR Organization*[ti])) }\end{array}$ \\
\hline \#7 Search & $\begin{array}{l}\text { Quality of Health Care[mh:noexp] OR Quality Assur- } \\
\text { ance, Health Care[mh:noexp] OR Quality Indicators, } \\
\text { Health Care[mh:noexp] OR Quality control[mh] OR } \\
\text { Quality[tiab] }\end{array}$ \\
\hline \#6 Search & Adopt*[tiab] OR Implement*[tiab] \\
\hline \#5 Search & $\begin{array}{l}\text { Attitude[mh] OR Attitude*[tiab] OR Accept* [tiab] OR } \\
\text { Barrier*[tiab] OR Difficult* [tiab] OR Facilitator [tiab] } \\
\text { OR Resist*[tiab] OR Usefulness[tiab] OR "Ease of use"[- } \\
\text { tiab] }\end{array}$ \\
\hline \#4 Search & \#1 OR (\#2 AND \#3) \\
\hline \#3 Search & $\begin{array}{l}\text { Colorectal neoplasms[mh] OR Colorectal cancer*[tiab] } \\
\text { OR Colorectal neoplasm*[tiab] OR Colorectal Tumor* } \\
\text { [tiab] OR Colorectal Carcinoma*[tiab] OR Colorectal } \\
\text { neoplasis*[tiab] }\end{array}$ \\
\hline \#2 Search & $\begin{array}{l}\text { Endoscopy[mh:noexp] OR Endoscopy, Digestive System } \\
\text { [mh:noexp] OR Endoscopy, gastrointestinal[mh:noexp] } \\
\text { OR Endoscop*[tiab] }\end{array}$ \\
\hline \#1 Search & $\begin{array}{l}\text { Colonoscopy[mh] OR Colonoscop*[tiab] OR Sigmoi- } \\
\text { doscop*[tiab] OR Proctosigmoidoscop*[tiab] }\end{array}$ \\
\hline
\end{tabular}

and experience is key to implementing CQI in healthcare services, patients also constitute an important group of users, whether implicitly or explicitly.

The objective of this mixed methods systematic review is to summarize knowledge with regard to barriers and facilitators to the successful implementation of CQI programs in colonoscopy units from the perspective of the endoscopists, nurses, managers, and patients. With respect to the CQI program, members of these four groups are all referred to as users. This synthesis will inform all stakeholders in order to prevent or mitigate issues during the implementation of colonoscopy CQI programs. It will also contribute to a mutual understanding of the factors affecting the adoption of CQI programs by other groups of users.

\section{Methods}

We conducted a mixed methods systematic review of the scientific literature published between 1 January 2000 and 31 May 2013 on barriers and facilitators perceived by any group of individuals, about itself or the three others (the four user groups are listed below under the subheading User groups), with a direct interest in the implementation of CQI programs in colonoscopy services. This type of review summarizes qualitative and quantitative research evidence with the same level of rigor [24].

\section{Search strategy}

We performed standardized literature searches on 15 relevant databases already described in the published study protocol [25] (see Table 1 for full electronic search strategy for Medline). We screened the references of the selected publications as a potential source of additional relevant articles. We also searched for other publications from the authors of the selected articles as well as publications citing the selected articles through the ISI Science Citation Index database.

\section{Selection criteria}

The studies included in this review should report barriers and facilitators with regard to implementing a CQI program, either as their primary outcome or as a secondary outcome related to the effects and impacts of CQI initiatives in colonoscopy. We define barriers and facilitators as technical, individual, organizational, and contextual factors that would facilitate or impede the implementation of such programs. Studies had to be based on an empirical design, using qualitative, quantitative or mixed methods, and had to use a structured and well described data collection process. Thus, we excluded studies reporting unstructured observations (defined as holistic, unstructured, and unfocused observations [26]), as well as editorials, comments, and position papers.

Implementations of CQI programs in colonoscopy services are defined as initiatives aiming at the improvement and maintenance of the quality and safety of the procedure (also called Clinical Quality and Safety) or at the enhancement of consumer care (also called Quality of Patient Experience). The selected studies could report on a pre, current or post implementation experience of a CQI program. We also considered the utilization of standards related to sigmoidoscopy and colonoscopy services.

\section{User groups}

The user groups are the four parties directly involved in the implementation of colonoscopy CQI programs, i.e. endoscopists (physicians, gastroenterologists, and surgeons), nurses, managers, and patients.

\section{Screening and data abstraction}

Pairs of authors (SG, MT, AB, BC, MPG) screened all titles and abstracts independently to assess compliance with inclusion criteria. We resolved discrepancies among reviewers on study inclusion through discussion with other team members. Full-text copies of relevant articles were independently reviewed by two authors (AB, MT) and were assessed for compliance with the selection criteria. One of the co-authors (CD), a gastroenterologist trained at the National Health Services (NHS), categorized the publications according to their specific focus using the Global Rating Scale (GRS) dimensions of colonoscopy services: appropriateness of colonoscopy, colonoscopy clinical quality, discharge process, patient satisfaction, patient compliance, and attitude towards the CQI program [12].

Then we extracted findings defining barriers and facilitators with respect to the implementation of CQI programs and the user group(s) it related to. Using a generic extraction grid based on previous works, we initially grouped the findings under distinct attributes best defining the type of the reported facilitators or barriers [27,28]. We gradually adapted the extraction grid through an iterative process based on consensus among the reviewers so as to adapt to the specific topic of this review. We relabeled some of the original attributes to provide a better de- 


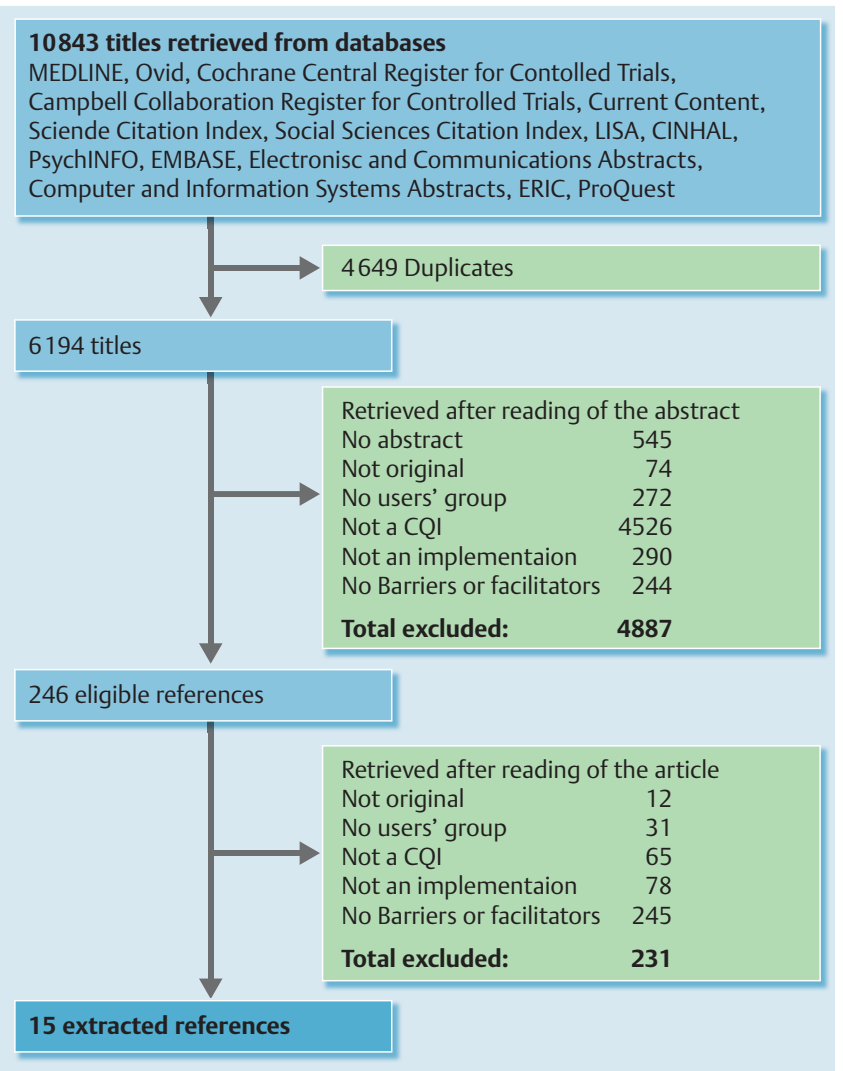

Fig. 1 Study selection flow chart.

scription of findings, adding emergent attributes and removing those not addressed by any of the selected publications. We further grouped attributes under three main themes: features of the CQI program, attitudes and perceptions, and organizational environment. We reported findings using consensual guidelines for narrative syntheses and meta-analytical techniques $[29,30]$. Finally, we presented findings in the form of a narrative synthesis [29].

\section{Appraisal of study quality}

We assessed the quality of all selected studies and each type of design using scales based on a recent tool that proposes criteria specific for quantitative (experimental and observational), qualitative, and mixed methods designs [31].

\section{Results}

$\nabla$

\section{Included studies}

We screened the titles and abstracts of the 6194 references identified through the search strategy. We retained a total of 246 publications for full-text analysis, of which 15 studies met the selection criteria [32-46]. The selection flow chart is depicted in - Fig. 1.

\section{Characteristics of included studies}

The characteristics of the 15 selected studies are summarized in - Table2. All studies were conducted in countries with comparable standards of living according to the Organisation for Economic Co-operation and Development (OECD): Australia [39, 42], the United Kingdom [32,43], the United States [33,44-46],
Italy [35,36], Norway [34,37], Canada [41], Israel [38], and the Netherlands [40]. The study design of 10 publications (67\%) is quantitative $[33-38,40,43,45,46]$; two $(13 \%)$ studies have a qualitative design [39, 41]; and the other three (20\%) use a mixed methods approach $[32,42,44]$. Most studies collected data either through questionnaires $(n=9,60 \%)[34,35,37,38,40,41,44-46]$ or audits $(n=4,27 \%)[32,36,42,43]$. The other two studies $(13 \%)$ report telephone surveys or document analyses [33,39]. A quality score of $100,75,50$, and $25 \%$ was allocated, to three, six, four, and two studies, respectively. Since findings extracted from the low-quality studies were comparable to those from studies of higher quality, no study was rejected based on the quality score.

\section{Extracted findings}

- Supplementary File 1 presents the 99 findings that were extracted from the 15 selected studies. Three major themes emerged from the iterative classification of the extracted findings. The first theme, features of CQI programs, includes 59 findings extracted from 14 studies and grouped under 11 distinct attributes. The second theme, attitudes and perceptions, was addressed by nine studies that provided 16 findings grouped under three attributes. Finally, 24 findings extracted from 10 studies fell under the third theme, organizational characteristics, divided into five distinct attributes ( $\bullet$ Table 3 ).

Most of the selected studies focus on the clinical quality of colonoscopies ( $n=11$ studies, 55 findings) [32,34-38,41,43-46], followed by appropriateness of colonoscopy ( $\mathrm{n}=3$ studies, 23 findings) $[33,41,42]$ and patient satisfaction ( $n=2$ studies, 9 findings) $[37,38]$. Attitude toward the CQI programs [40], quality of the discharge process [39], and patient compliance [38] are addressed in only one study each, providing 16 findings, four findings, and one finding, respectively.

\section{User groups}

- Table 3 presents the themes and attributes according to each user group with which they are associated. Among the four user groups, the endoscopists were by far the most studied (13 out of 15 studies), and most of the extracted findings are associated with this group (64 findings extracted, $65 \%$ ). Their perspective dominates the attributes related to the features of CQI programs (12 studies and 44 out of 59 findings, $75 \%$ ), and those related to attitudes and perceptions ( 8 studies and 14 out of 16 findings, $88 \%$ ). Management is largely associated with the third theme, namely the organizational characteristics of CQI programs, where 10 out of the 17 findings (59\%) associated with this user group are categorized. Findings related to nurses and patients represent only $18 \%$ of all extracted findings. Eight studies consider nurses' perspective (9 findings, 10\%), and five studies account for the patients' experience ( 9 findings, $9 \%$ ).

"Involving all users in the planning and implementation of CQI programs" is the only attribute shared across the four user groups. "Feasibility and adaptability" as well as "training and education" are reported for three out of the four user groups (endoscopists, patients and either management or nurses, respectively). Six other attributes are associated with two user groups (three with endoscopists and nurses, two with endoscopists and patients, and one with endoscopists and management). Finally, seven and four attributes were exclusively documented in association with endoscopists and management, respectively. There was no attribute exclusive to nurses. 


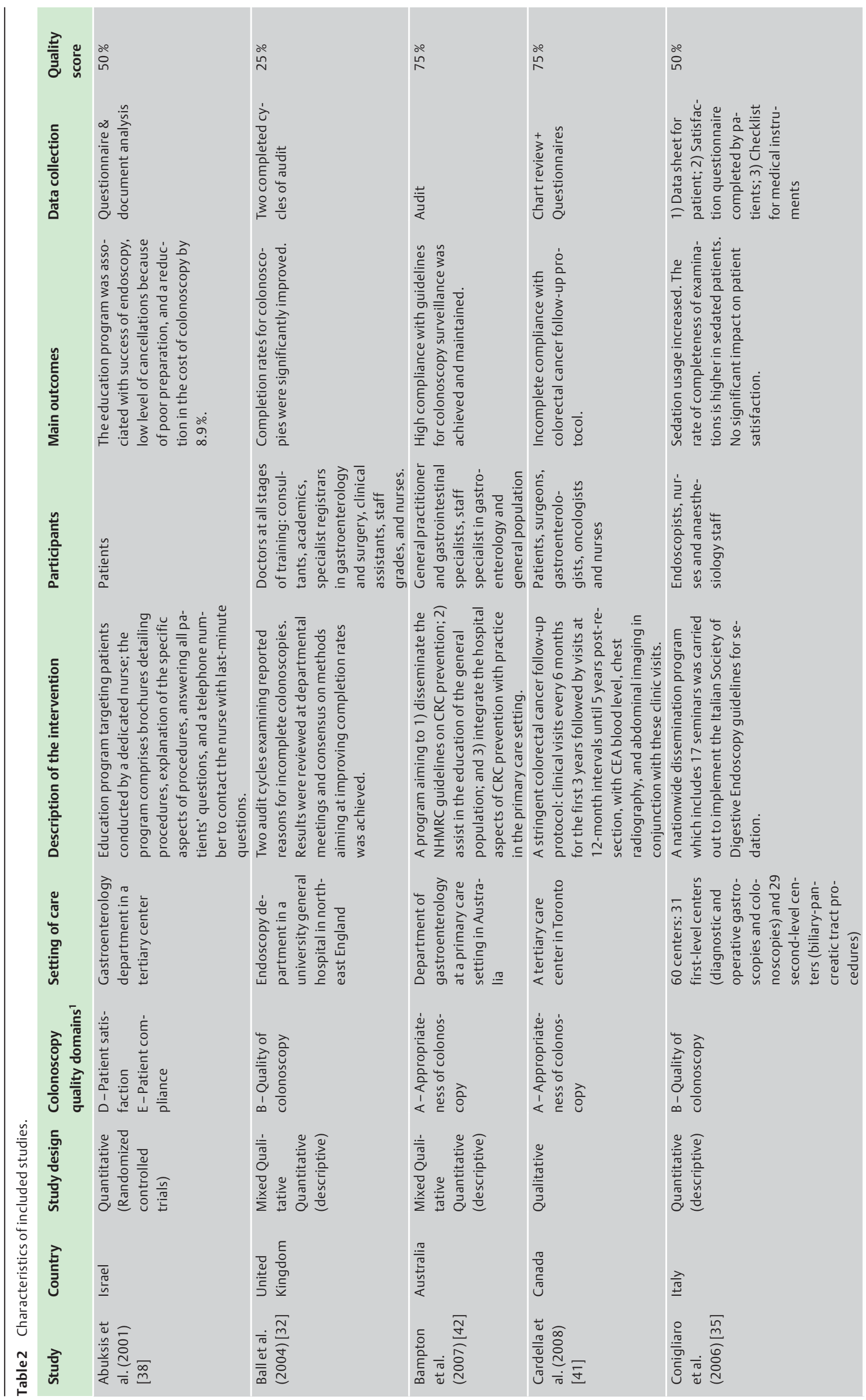




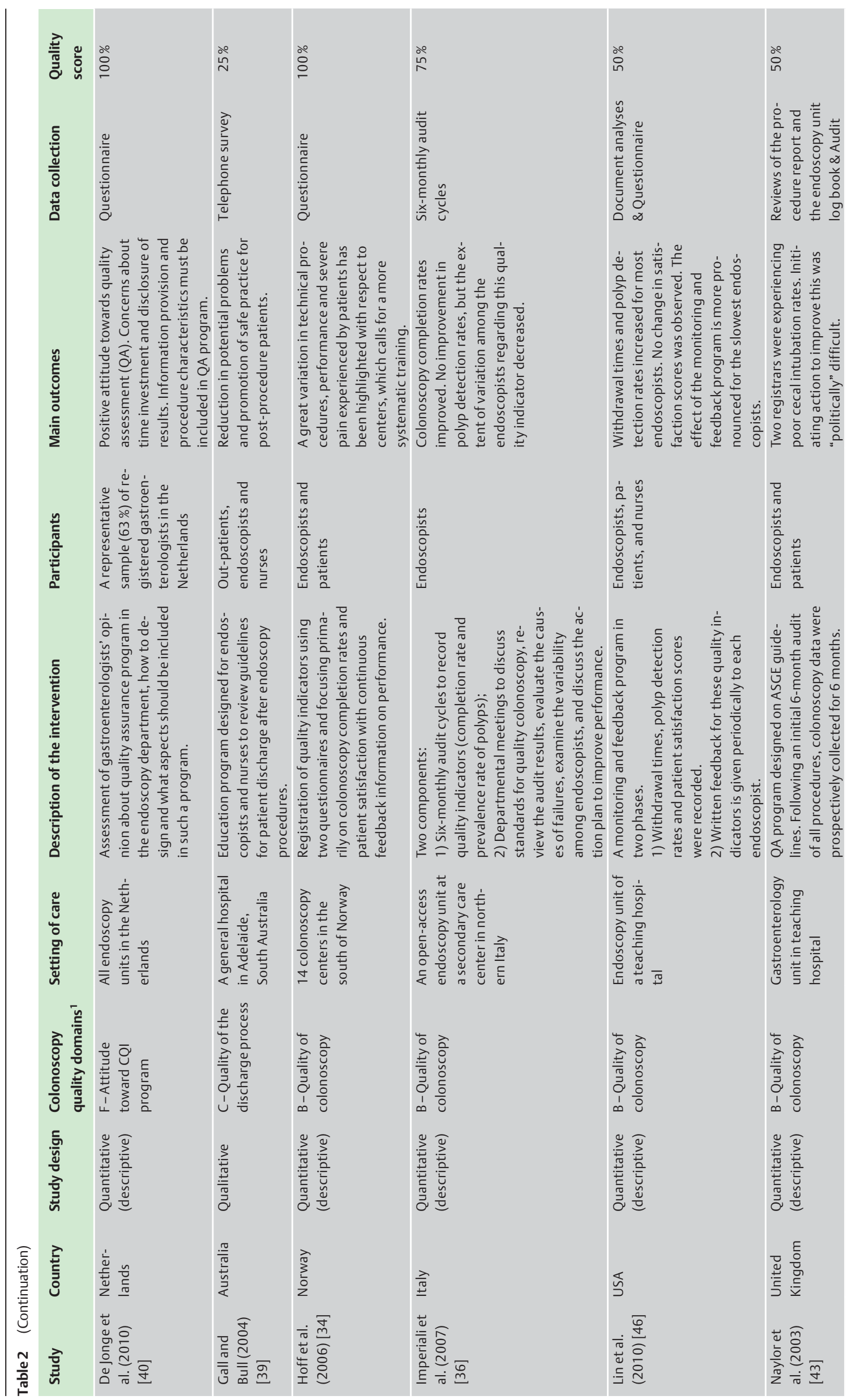




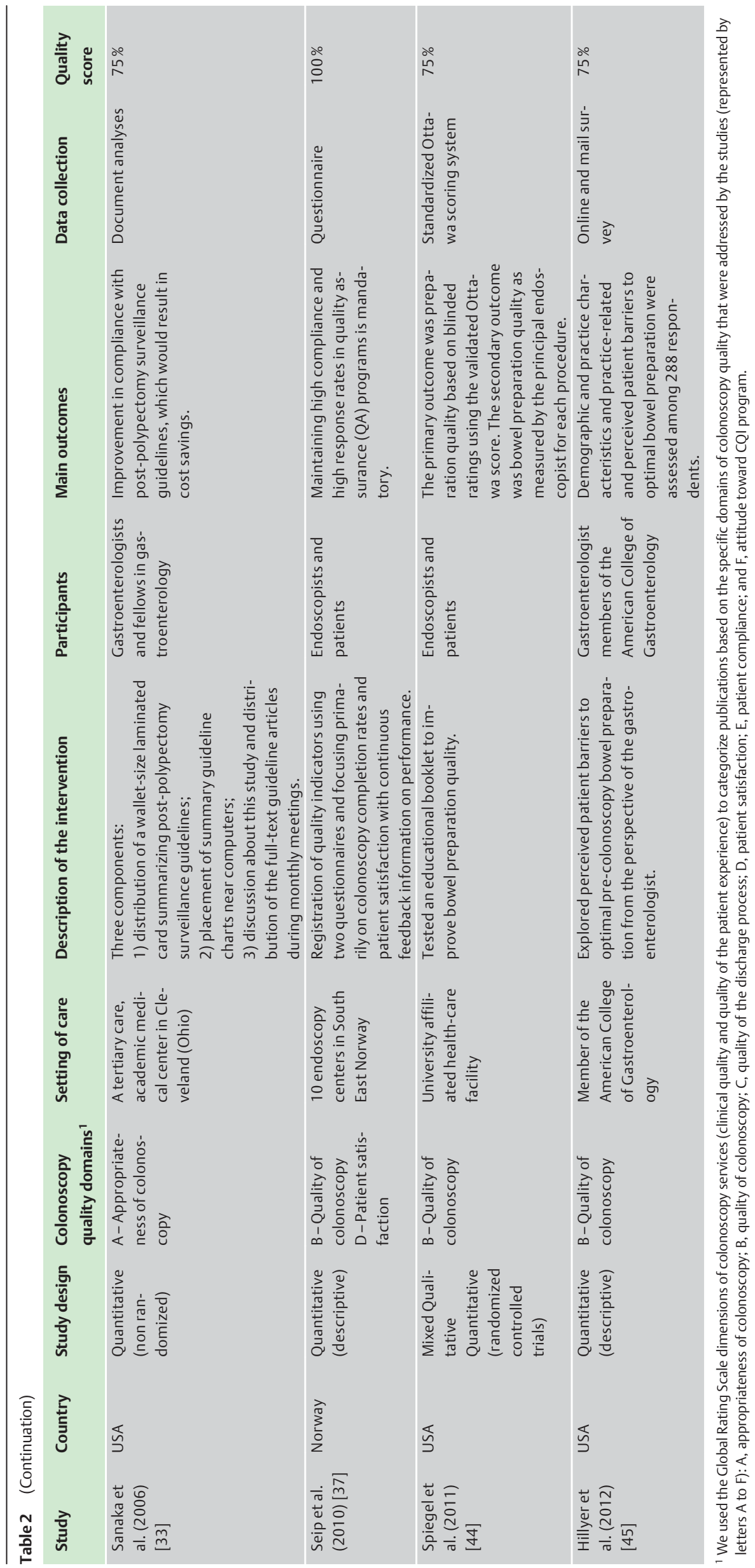


Table 3 Number of extracted items and number of articles in which they were identified according to major themes and attributes for each user group.

\begin{tabular}{|c|c|c|c|c|c|}
\hline & \multicolumn{5}{|c|}{ Number of items/Number of articles } \\
\hline & Endoscopists & Nurses & Management & Patients & Total \\
\hline 1. Features of the CQI program & $44 / 12$ & $2 / 2$ & $7 / 4$ & $6 / 3$ & $59 / 14$ \\
\hline 1.01 Voluntary participation & $2 / 2$ & & & & $2 / 2$ \\
\hline 1.02 Summative and formative evaluation & $6 / 6$ & & & & $6 / 6$ \\
\hline 1.03 Disclosure of results & $10 / 7$ & & & & $10 / 7$ \\
\hline 1.04 Quality indicators & $7 / 5$ & & & & $7 / 5$ \\
\hline 1.05 Training and education & $5 / 5$ & $1 / 1$ & & $1 / 1$ & $7 / 6$ \\
\hline 1.06 Patient centered & $2 / 1$ & & & $1 / 1$ & $3 / 2$ \\
\hline 1.07 Clinical quality centered & $1 / 1$ & & & & $1 / 1$ \\
\hline 1.08 Feasibility and adaptability & $5 / 3$ & & $2 / 2$ & $4 / 2$ & $11 / 5$ \\
\hline 1.09 Clarity of the intervention & $3 / 3$ & $1 / 1$ & & & $4 / 3$ \\
\hline 1.10 Cost and cost-effectiveness & $1 / 1$ & & $5 / 4$ & & $6 / 5$ \\
\hline 1.11 Maintaining of compliance & $2 / 2$ & & & & $2 / 2$ \\
\hline 2. Attitudes and perceptions & $14 / 8$ & $1 / 1$ & & $1 / 1$ & $16 / 9$ \\
\hline 2.01 Attitude towards intervention or the action plan & $8 / 6$ & & & & $8 / 6$ \\
\hline 2.02 Sense of ownership as regards the intervention & $3 / 3$ & $1 / 1$ & & & $4 / 3$ \\
\hline 2.03 Perception of impact & $3 / 1$ & & & $1 / 1$ & $4 / 2$ \\
\hline 3. Organizational characteristics & $6 / 6$ & $6 / 6$ & $10 / 8$ & $2 / 2$ & $24 / 10$ \\
\hline 3.01 Involving all in the planning and implementation & $5 / 5$ & $4 / 4$ & $2 / 2$ & $2 / 2$ & $13 / 5$ \\
\hline 3.02 Support from hospital administration & & & $2 / 2$ & & $2 / 2$ \\
\hline 3.03 Dedicating staff to perform new roles & $1 / 1$ & $2 / 2$ & & & $3 / 3$ \\
\hline 3.04 Access to human resources & & & $1 / 1$ & & $1 / 1$ \\
\hline 3.05 Access to material & & & $3 / 3$ & & $3 / 3$ \\
\hline 3.06 Access to training & & & $2 / 2$ & & $2 / 2$ \\
\hline Total & $64 / 13$ & $9 / 8$ & $17 / 9$ & $9 / 5$ & $99 / 15$ \\
\hline
\end{tabular}

\section{Features of the colonoscopy CQI programs}

When it comes to implementing CQI, the features of the CQI programs are most important for endoscopists as confirmed in 12 $(80 \%)$ out of 15 studies. The attribute most often cited in relation to endoscopists is "ensuring confidentiality of individuals' quality assessment results" (10 findings) [32,34,36,37,40,43,46]; followed by the utilization of "quality indicators" (7 findings) [34, $36,37,40,43]$; "training and education" (7 findings) [32-34,36, 39]; and "formative evaluation" (6 findings) $[32-34,36,38,43]$. The "clarity of the intervention" expressed in comprehensive, clear, and simple guidelines covering all clinical situations and clearly depicting responsibilities is deemed critical by endoscopists and nurses $[33,41,42]$. Better compliance with the guidelines is reported when these two user groups are involved in their development [42].

Concerns about "feasibility and adaptability", an attribute shared by endoscopists, management, and patients is the most frequently cited among the features of the CQI program (11 findings) [33, $42-45]$.

Unsurprisingly, "cost and cost-effectiveness" issues are mainly reported by management $[32,33,38,43]$. However, the necessity to invest resources (time, money, and personnel) is also acknowledged by management [43].

Finally, "maintaining compliance" with a CQI program is identified as a challenge $[37,42]$. The absence, right from its inception, of explicit features favoring the integration of the CQI program into routine activities is detrimental $[37,42]$. Nevertheless, no facilitating approach is suggested to overcome this barrier.
Attitudes and perceptions concerning CQI programs

"Attitudes toward the intervention" are reported by endoscopists as an influential attribute in eight (53\%) out of 15 studies. Some studies documented the facilitating effect of a positive attitude $[32,34,35]$ while others confirmed that a negative attitude was a barrier $[35,38,42]$. The longer the experience, the more positive the endoscopists' attitude seems to be [40]. Similarly, "sense of ownership" $[33,34,37]$ and "perception of the (potentially positive) impact" on the quality and capacity of endoscopy units [34] have a positive influence on implementation. The positive relationship with "sense of ownership" is also documented for nurses [37]. None of the included papers contained findings pertaining to the attitudes and perceptions of managers.

\section{Organizational environment}

"Involving all users in the planning and implementation" of the CQI program is the most frequent finding and the only one common to all user groups $[32,33,40,41,43]$. Four of the other five attributes under this theme are exclusively associated with management role in the provision of support and resources: "support from the administration", for example, in explicitly adopting guidelines or planning no clinical activities during CQI meetings $[33,39]$ and ensuring appropriate "access to human resources and material" $[35,41,43]$ as well as "access to training" [34,39]. The favorable influence of ensuring that new roles required by the implementation of CQI programs are specifically assigned to dedicated staff is deemed important to both endoscopists and nurses $[36,42,43]$. 
Table 4 Summary table of the main findings of the review.

\begin{tabular}{|c|c|}
\hline Strength of finding & Main message \\
\hline \multirow[t]{3}{*}{$\begin{array}{l}\text { Most recurrent findings }(\geq 10) \text { in } \\
\text { at least a third }(\geq 5) \text { of the select- } \\
\text { ed studies }\end{array}$} & $\begin{array}{l}\text { All user groups should be involved in the CQI program implementation and follow-up (endoscopists, nurses, man- } \\
\text { agers, and patients) to ensure the appropriateness of the program in regards to all important aspects impacting on } \\
\text { quality. } \\
\text { (Re: all users' groups) }\end{array}$ \\
\hline & $\begin{array}{l}\text { Guidelines, standards, and procedures must be reviewed and adapted locally to ensure feasibility. Otherwise, they can } \\
\text { be counterproductive and be detrimental to quality. } \\
\text { (Re: endoscopists, managers, and patients) }\end{array}$ \\
\hline & $\begin{array}{l}\text { The confidentiality of results regarding the quality performance of individual endoscopists seems to be a prerequisite } \\
\text { to the implementation of a CQI program. } \\
\text { (Re: endoscopists) }\end{array}$ \\
\hline \multirow[t]{5}{*}{$\begin{array}{l}\text { Recurrent findings }(<10, \geq 5) \text { in at } \\
\text { least a third }(\geq 5) \text { of the selected } \\
\text { studies }\end{array}$} & $\begin{array}{l}\text { The CQI program must be aiming at enhancing and maintaining the quality of the colonoscopy unit and not at tackling } \\
\text { poor performers. Issues are better resolved through discussions and mutual understanding. } \\
\text { (Re: endoscopists) }\end{array}$ \\
\hline & $\begin{array}{l}\text { Systematically collecting information to produce indicators and evaluate quality is deemed necessary. However, time } \\
\text { and efforts required to do so must be minimized and the indicators need to be meaningful to allow identification of } \\
\text { potential issues and successful resolutions. } \\
\text { (Re: endoscopists) }\end{array}$ \\
\hline & $\begin{array}{l}\text { Implementation of CQI programs requires that personnel be instructed and trained for all modifications to their duties. } \\
\text { Individual and collective reviews of performance and audit results are part of training. Offering support to those having } \\
\text { difficulties is the favored approach. } \\
\text { (Re: endoscopists, nurses and managers) }\end{array}$ \\
\hline & $\begin{array}{l}\text { Administration must agree that there are resources involved in the implementation of CQI programs. However, it is } \\
\text { reported that expenses can be minimal and that CQI programs were found cost-effective. } \\
\text { (Re: managers) }\end{array}$ \\
\hline & $\begin{array}{l}\text { Implementation of a CQI program must foster a positive attitude, especially from the part of the endoscopist. Being } \\
\text { inclusive of all stakeholders, voluntary participation, production of indicators, and confidentiality of evaluation results } \\
\text { are among the important features that can create a favorable attitude while mitigating the negative effects of too } \\
\text { much self-confidence. } \\
\text { The more experienced endoscopists tend to have a better attitude. } \\
\text { (Re: endoscopists) }\end{array}$ \\
\hline
\end{tabular}

\section{Main messages}

The extraction of the attributes according to the three major themes ( $\bullet$ Table 3$)$, associated with the quotes extracted from the selected publications, allows formulating the main messages from these empirical studies. $\triangle$ Table 4 lists the main findings (observations appearing at least five times in at least five different studies) that emerge from this review. The vast majority of the other findings are particular instances of the more general messages of $\bullet$ Table 4 .

\section{Discussion}

\section{$\nabla$}

This review pinpoints specific attributes consistently reported by empirical studies to facilitate the successful implementation of CQI initiatives in colonoscopy services. The findings are consistent with several constructs of current models of adoption and implementation of innovations in healthcare by validating the advantage of a clearly defined, voluntary, participatory, and formative approach that is adaptable and agreeable to the different user groups involved. CQI initiatives relying on a team effort inclusive of all user groups, implemented in supportive organizations, and providing adequate resources are more likely to succeed.

Extracting and analyzing facilitators and barriers of the implementation process with respect to each user group reveal that their specific roles and contributions have not yet been adequately assessed by research. Significant knowledge gaps remain with respect to barriers and facilitators associated with patients and nurses resulting from a lack of appropriate consideration of these groups in most studies.

Implementation of $\mathrm{CQI}$ is a process aiming at the achievement and maintenance of standard of performance, persuading individuals to all contribute to the clinical quality, and enhance the patient's experience by maximizing the benefits with the minimum harm [21]. Even though the review confirms that all groups acknowledged the importance of managers', nurses' and patients' involvement, the perspective of non-clinicians remains understudied. Considering patients as full partners apparently remains a challenge, and although patient satisfaction was the explicit focus of two of the included studies, it was not addressed from the patient's perspective $[37,38]$. This is clearly in contrast to current knowledge in the field of implementation of innovations in clinical practice $[18,47,48]$, even if two of the most recent studies offer insightful findings with respect to the perspective of patients when analyzing the feasibility of CQI programs and the need for training and education $[44,45]$.

With the increasing role of nurses in clinical procedures, it is surprising that their perspective had very little echo in studies on the implementation of CQI colonoscopy initiatives. The fact that none of the facilitators or barriers identified through this review was exclusive to nurses is likely an indication that the role of nurses has not been addressed as a distinct contribution to CQI programs. However, the critical role of lead nurses in the quality enhancement of an endoscopy service is one of the key lessons learned from the British experience [21]. During the implementation of a colonoscopy CQI program, nurses are expected to renew the definition of their roles and work procedures as well as 
to adopt new models of relationships with patients and endoscopists.

Our results also highlight the responsibilities of organizations in the implementation of CQI initiatives. Organizational characteristics such as the involvement of all user groups in the implementation of the CQI program as well as support from hospital administration and access to training are reported to be important management roles $[32-34,39,40,43]$. Studies on adoption of innovations also suggest that tangible management support is a prominent feature of successful adoptions of innovation [48]. It is known that the extent to which innovative interventions will be expected, supported, and acknowledged contributes to a favorable inner organizational environment [18]. In fact, Greenhalgh et al. indicate that these characteristics reflect on system readiness, which emphasizes their role as pre-existing favorable factors rather than merely accompanying or following the initiative [18].

Knowledge translation and innovation adoption models stress the critical role of monitoring in a successful implementation, sometimes referred to as the confirmation phase $[18,48]$. In his recent review of the English endoscopy CQI program, Valori insists on the essential quality assurance component of colonoscopy quality improvement programs, although he warns against the reluctance of physicians to accept monitoring [23]. Our review confirms that summative assessment based on quality indicators facilitates quality improvement. However, the acceptability of such a practice is conditional upon voluntary participation, using non-punitive approaches, preserving the confidentiality of individuals' results, and limiting the number of indicators that are collected $[34,36,37,40,43,46]$.

Attributes supported by almost half of the studies refer to the non-disclosure of physicians' individual results to quality assessment $[32,34,36,37,40,43,46]$; the positive attitude toward the intervention or the action plan [32,33,35,37,38,40-43]; and the involvement of all stakeholders in the planning and implementation of a CQI program $[32,33,41,43]$. These seem crucial to lever clinical leadership and engagement and are consistent with the overall value of mutual respect conveyed by most of the attributes identified through this review. These factors contribute to the quality of internal relationships that can positively influence implementation, and that have been described as possibly more important than individual attributes $[18,49,50]$.

The importance of the formative approach is further acknowledged by the positive impact of incorporating education and training for endoscopists and nurses, including mentoring by peers, as part of a CQI program [32-34,36,37,39]. Providing individualized and intensive support to the most challenged endoscopy provider sites and developing and supporting sites to create an achievable action plan for reform are key elements of a successful development of endoscopy CQI in England [21]. Formative approach, administrative support, and availability of sufficient resources (human and material) are facilitating attributes that advocate for the creation of supportive environments.

\section{Competing interests: None}

Institutions

${ }^{1}$ Institut d'excellence en santé et services sociaux du Québec, Quebec City, Quebec, Canada

${ }^{2}$ Université Laval - Department of Social and Preventive Medicine, Quebec City, Quebec, Canada

${ }^{3}$ Université de Montréal - Department of Medicine, Montreal, Quebec, Canada

${ }^{4}$ Maisonneuve-Rosemont Hospital - Gastroenterology, Montreal, Quebec, Canada

${ }^{5}$ University of Calgary - Department of Community Health Sciences, Calgary, Alberta, Canada

${ }^{6}$ CHU de Québec Research Center - Public Health and Practice-Changing Research, Quebec City, Quebec, Canada

${ }^{7}$ Université Laval - Faculty of Nursing, Quebec City, Quebec, Canada

${ }^{8}$ CHU de Québec Research Center - Population Health and Optimal Health

Practices, Quebec City, Quebec, Canada

\section{Acknowledgments}

$\nabla$

This study is funded by the Canadian Institutes of Health Research (CIHR) (grant \# 200905KR8-205038-KRS-CFCC-168527).

\section{References}

1 Leddin D, Hunt R, Champion M et al. Canadian Association of Gastroenterology and the Canadian Digestive Health Foundation: Guidelines on colon cancer screening. Can J Gastroenterol 2004; 18: 93 -99

2 DeGroff A, Boehm J, Goode Green S et al. Facilitators and challenges to start-up of the colorectal cancer screening demonstration program. Prev Chronic Dis 2008; 5: A39

3 Pignone $M$. Challenges in implementation of effective and efficient colon cancer screening. Dig Liver Dis 2007; 39: 251 - 252

4 Shaukat A, Mongin SJ, Geisser MS et al. Long-term mortality after screening for colorectal cancer. New Engl J Med 2013; 369: 1106 1114

5 Miller A, Candas B, Berthelot JM et al. Pertinence et faisabilité d'un programme de dépistage du cancer colorectal au Québec [Relevance and feasibility of a colorectal cancer screening program in Quebec]. Quebec City: Institut national de santé publique du Québec; 2009

6 Colorectal cancer screening advisory group. Report of the Colorectal Cancer Screening Advisory Group. Wellington: Ministry of Health; 2006

7 Misra T, Lalor E, Fedorak RN. Endoscopic perforation rates at a Canadian university teaching hospital. Can J Gastroenterol 2004; 18: 221 - 226

8 Singh H, Turner D, Xue L et al. Risk of developing colorectal cancer following a negative colonoscopy examination: evidence for a 10-year interval between colonoscopies. JAMA 2006; 295: 2366-2373

9 Zappa M, Castiglione G, Grazzini G et al. "Does fecal occult blood testing really reduce mortality? A reanalysis of systematic review data." by Moayyedi P and Achkar E Am J Gastroenterol 2006; 101: 2433-2434

10 Hewitson P, Glasziou P, Irwig L et al. Screening for colorectal cancer using the faecal occult blood test, Hemoccult. Cochrane Database Syst Rev 2007: CD001216

11 Kahi CJ, Azzouz F, Juliar BE et al. Survival of elderly persons undergoing colonoscopy: implications for colorectal cancer screening and surveillance. Gastrointest Endosc 2007; 66: 544-550

12 National Endoscopy Team. Endoscopy Global Rating Scale. Available at: https://www.jagaccreditation.org/Page.aspx?ID=5 Accessed June 6, 2015

13 Strul H, Kariv R, Leshno $M$ et al. The prevalence rate and anatomic location of colorectal adenoma and cancer detected by colonoscopy in average-risk individuals aged 40-80 years. Am J Gastroenterol 2006; 101: $255-262$

14 Winawer SJ, Zauber AG, Fletcher RH et al. Guidelines for colonoscopy surveillance after polypectomy: a consensus update by the US MultiSociety Task Force on Colorectal Cancer and the American Cancer Society. Gastroenterology 2006; 130: $1872-1885$

15 Sewitch MJ, Dube C, Brien $S$ et al. Patient-identified quality indicators for colonoscopy services. Can J Gastroenterol 2013; 27: 25-32

16 Nadeem E, Olin SS, Hill LC et al. Understanding the components of quality improvement collaboratives: a systematic literature review. Milbank Q 2013; 91: 354 - 394

17 Sollecito WA, Johnson JK. Factors influencing the application and diffusion of CQI in health care. In: Sollecito WA, Johnson JK (eds.) McLaughlin and Kaluzny's Continuous Quality Improvement in Health Care. 4th edn. Burlington, MA: Jones \& Bartlett Publishers; 2011: 49-74 
18 Greenhalgh T, Robert G, Macfarlane F et al. Diffusion of innovations in service organizations: systematic review and recommendations. Milbank Q 2004; 82: 581 - 629

19 Greenhalgh T, Robert G, Bate P et al. Diffusion of innovations in health service organisations: a systematic literature review. Malden, MA: Blackwell Publishing; 2008

20 Hilsden RJ, Rostom A, Dube C et al. Development and implementation of a comprehensive quality assurance program at a community endoscopy facility. Can J Gastroenterol 2011; 25: 547-554

21 Stebbing JF. Quality assurance of endoscopy units. Best Pract Res Clin Gastroenterol 2011; 25: 361 - 370

22 Bosch $M$, van der Weijden T, Wensing $M$ et al. Tailoring quality improvement interventions to identified barriers: a multiple case analysis. J Eval Clin Pract 2007; 13: 161 - 168

23 Valori R. Quality improvements in endoscopy in England. Tech Gastrointest Endosc 2012; 14: 63-72

24 Hemingway $P$, Brereton $N$. What is a systematic review? Available at http://www.medicine.ox.ac.uk/bandolier/painres/download/whatis/ syst-review.pdf (Accessed June 6, 2015)

25 Jobin G, Gagnon MP, Candas B et al. User's perspectives of barriers and facilitators to implementing quality colonoscopy services in Canada: a study protocol. Implement Sci 2010; 5: 85

26 McKechnie LEF. Unstructured observation. In: Given LM (ed.) The SAGE Encyclopedia of Qualitative Research Methods. Thousand Oaks, CA: SAGE Publications; 2008: 1072

27 Gagnon MP, Desmartis M, Labrecque $M$ et al. Systematic review of factors influencing the adoption of information and communication technologies by healthcare professionals. J Med Syst 2010; 36: $241-277$

28 McGinn CA, Grenier S, Duplantie J et al. Comparison of user groups' perspectives of barriers and facilitators to implementing electronic health records: a systematic review. BMC Med 2011; 9: 46

29 Mays $N$, Pope C, Popay J. Systematically reviewing qualitative and quantitative evidence to inform management and policy-making in the health field. J Health Serv Res Policy 2005; 10: 016-20

30 The Cochrane Collaboration, JBI Research Unit. Cochrane Qualitative Research Methods Group. Available at http://cqim.cochrane.org/ (Accessed June 6, 2015)

31 Pace $R$, Pluye $P$, Bartlett $G$ et al. Testing the reliability and efficiency of the pilot Mixed Methods Appraisal Tool (MMAT) for systematic mixed studies review. Int J Nurs Stud 2012; 49: 47-53

32 Ball JE, Osbourne J, Jowett $S$ et al. Quality improvement programme to achieve acceptable colonoscopy completion rates: prospective before and after study. BMJ 2004; 329: 665 - 667

33 Sanaka MR, Super DM, Feldman ES et al. Improving compliance with postpolypectomy surveillance guidelines: an interventional study using a continuous quality improvement initiative. Gastrointest Endosc 2006; 63: $97-103$

34 Hoff G, Bretthauer M, Huppertz-Hauss G et al. The Norwegian Gastronet project: Continuous quality improvement of colonoscopy in 14 Norwegian centres. Scand J Gastroenterol 2006; 41: 481 - 487
35 Conigliaro R, Rossi A Italian Society of Digestive Endoscopy (SIED) Sedation Commission. Implementation of sedation guidelines in clinical practice in Italy: results of a prospective longitudinal multicenter study. Endoscopy 2006; 38: 1137 - 1143

36 Imperiali G, Minoli G, Meucci GM et al. Effectiveness of a continuous quality improvement program on colonoscopy practice. Endoscopy 2007; 39: $314-318$

37 Seip B, Bretthauer M, Dahler S et al. Sustaining the vitality of colonoscopy quality improvement programmes over time. Experience from the Norwegian Gastronet programme. Scand J Gastroenterol 2010; 45 : $362-369$

38 Abuksis G, Mor M, Segal N et al. A patient education program is cost-effective for preventing failure of endoscopic procedures in a gastroenterology department. Am J Gastroenterol 2001; 96: 1786 - 1790

39 Gall S, Bull J. Clinical risk: discharging patients with no-one at home. Gastroenterol Nurs 2004; 27: 111 - 114

40 De Jonge V, Nicolaas JS, Van Leerdam ME et al. The opinion of gastroenterologists towards quality assurance in endoscopy. Gastrointest Endosc 2010; 71: AB219

41 Cardella J, Coburn NG, Gagliardi A et al. Compliance, attitudes and barriers to post-operative colorectal cancer follow-up. J Eval Clin Pract 2008; 14: $407-415$

42 Bampton PA, Sandford JJ, Young GP. Achieving long-term compliance with colonoscopic surveillance guidelines for patients at increased risk of colorectal cancer in Australia. Int J Clin Pract 2007; 61: 510 - 513

43 Naylor G, Gatta L, Butler A et al. Setting up a quality assurance program in endoscopy. Endoscopy 2003; 35: $701-707$

44 Spiegel BM, Talley J, Shekelle P et al. Development and validation of a novel patient educational booklet to enhance colonoscopy preparation. Am J Gastroenterol 2011; 106: 875 - 883

45 Hillyer GC, Basch CH, Basch CE et al. Gastroenterologists' perceived barriers to optimal pre-colonoscopy bowel preparation: results of a national survey. J Cancer Educ 2012; 27: 526-532

46 Lin OS, Kozarek RA, Arai A et al. The effect of periodic monitoring and feedback on screening colonoscopy withdrawal times, polyp detection rates, and patient satisfaction scores. Gastrointest Endosc 2010; 71 : $1253-1259$

47 Damschroder LJ, Aron DC, Keith RE et al. Fostering implementation of health services research findings into practice: a consolidated framework for advancing implementation science. Implement Sci 2009; 4 50

48 Feldstein AC, Glasgow RE. A practical, robust implementation and sustainability model (PRISM) for integrating research findings into practice. Jt Comm J Qual Patient Saf 2008; 34: 228 - 243

49 Plsek PE, Wilson T. Complexity, leadership, and management in healthcare organisations. BMJ 2001; 323: 746-749

50 Safran DG, Miller W, Beckman $H$. Organizational dimensions of relationship-centered care. J Gen Intern Med 2006; 21: 9-S15 


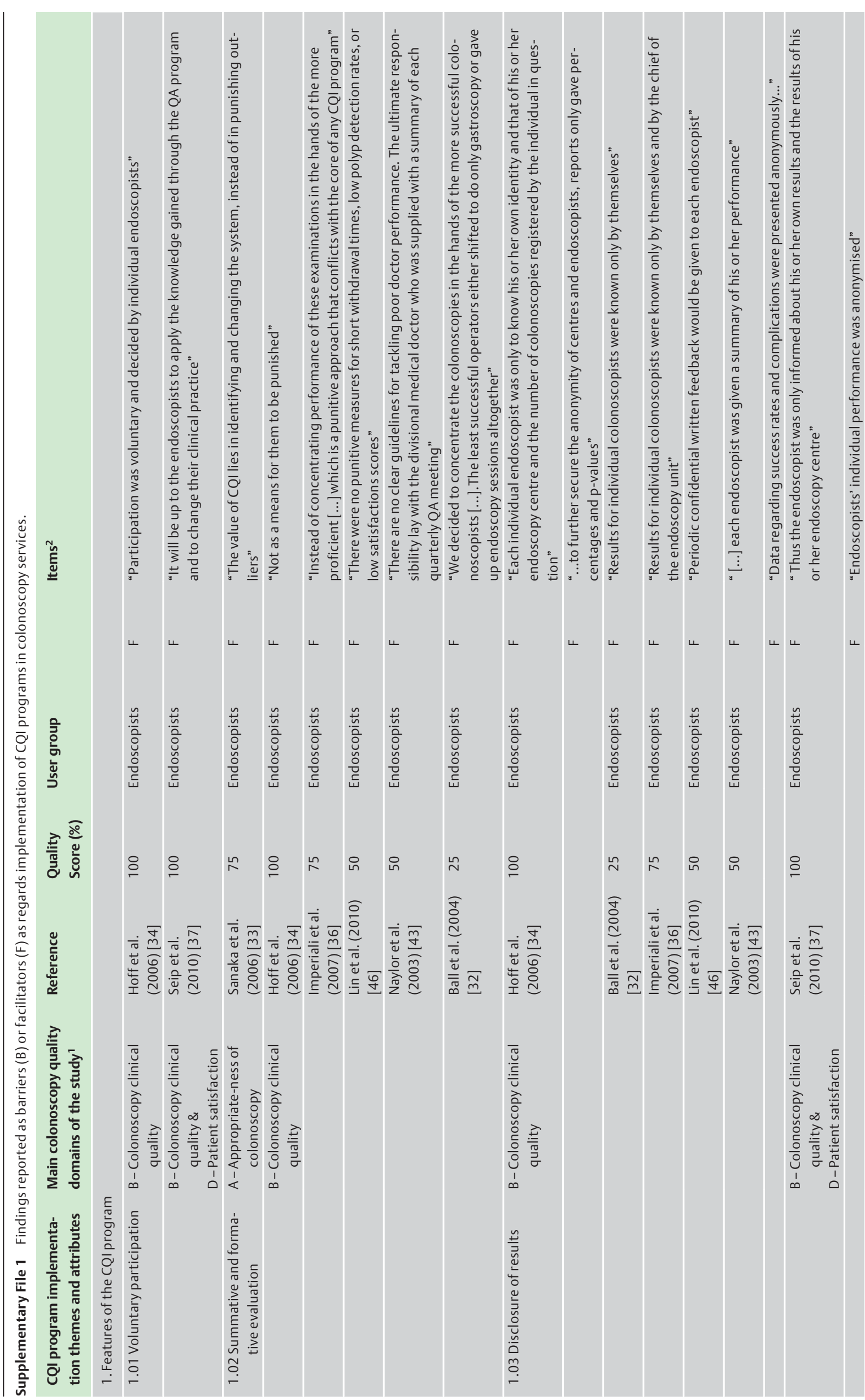




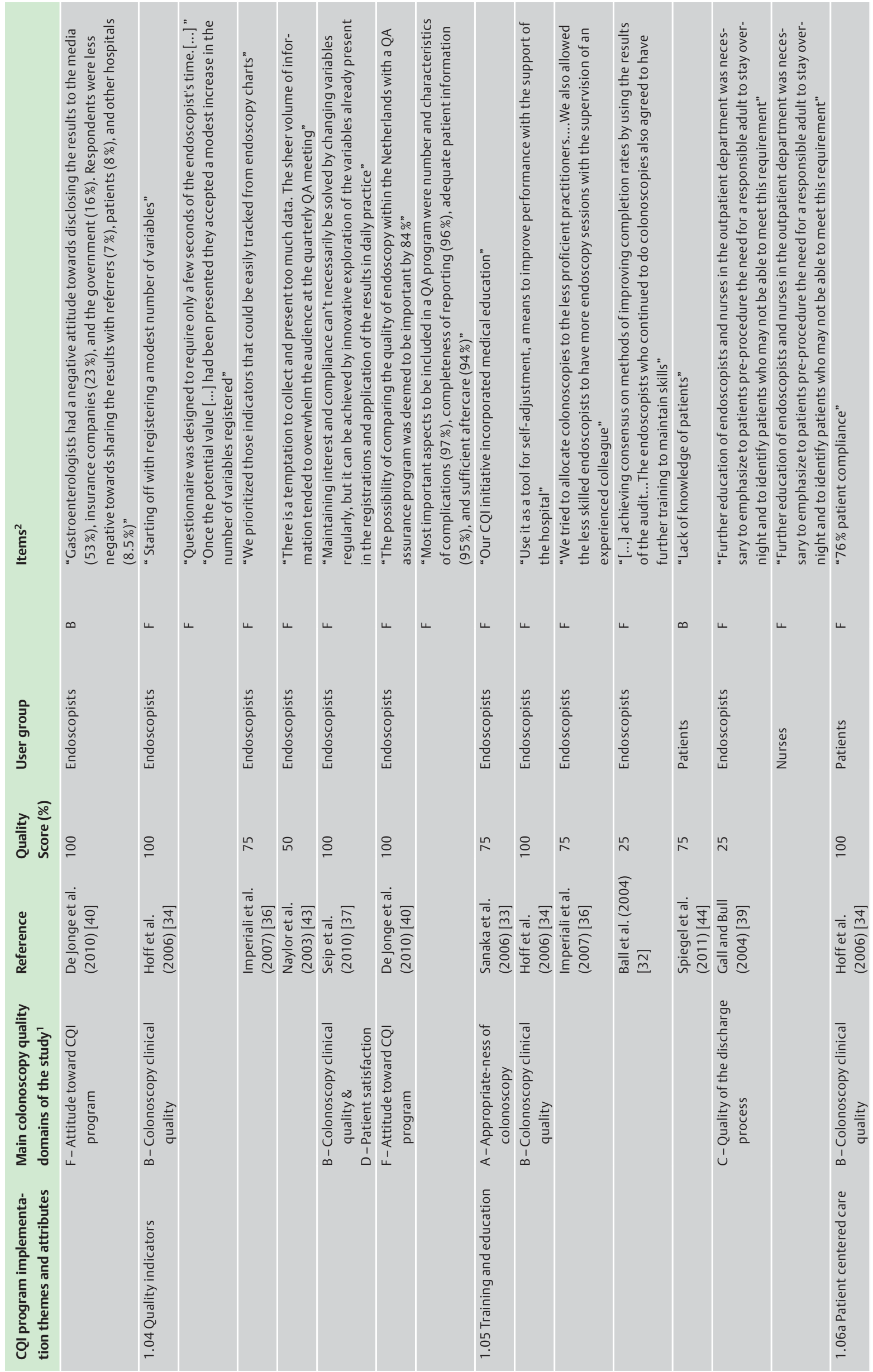




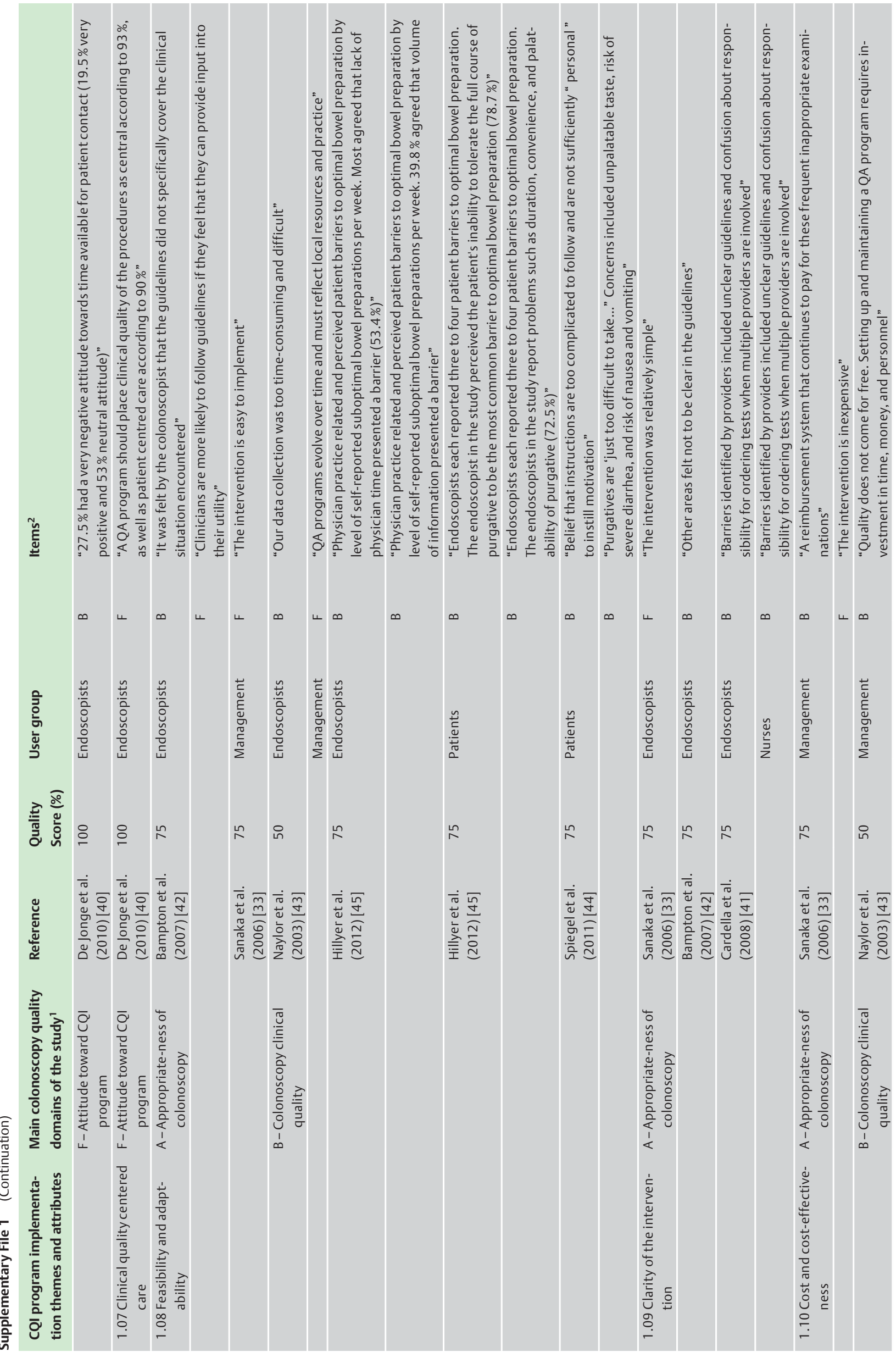




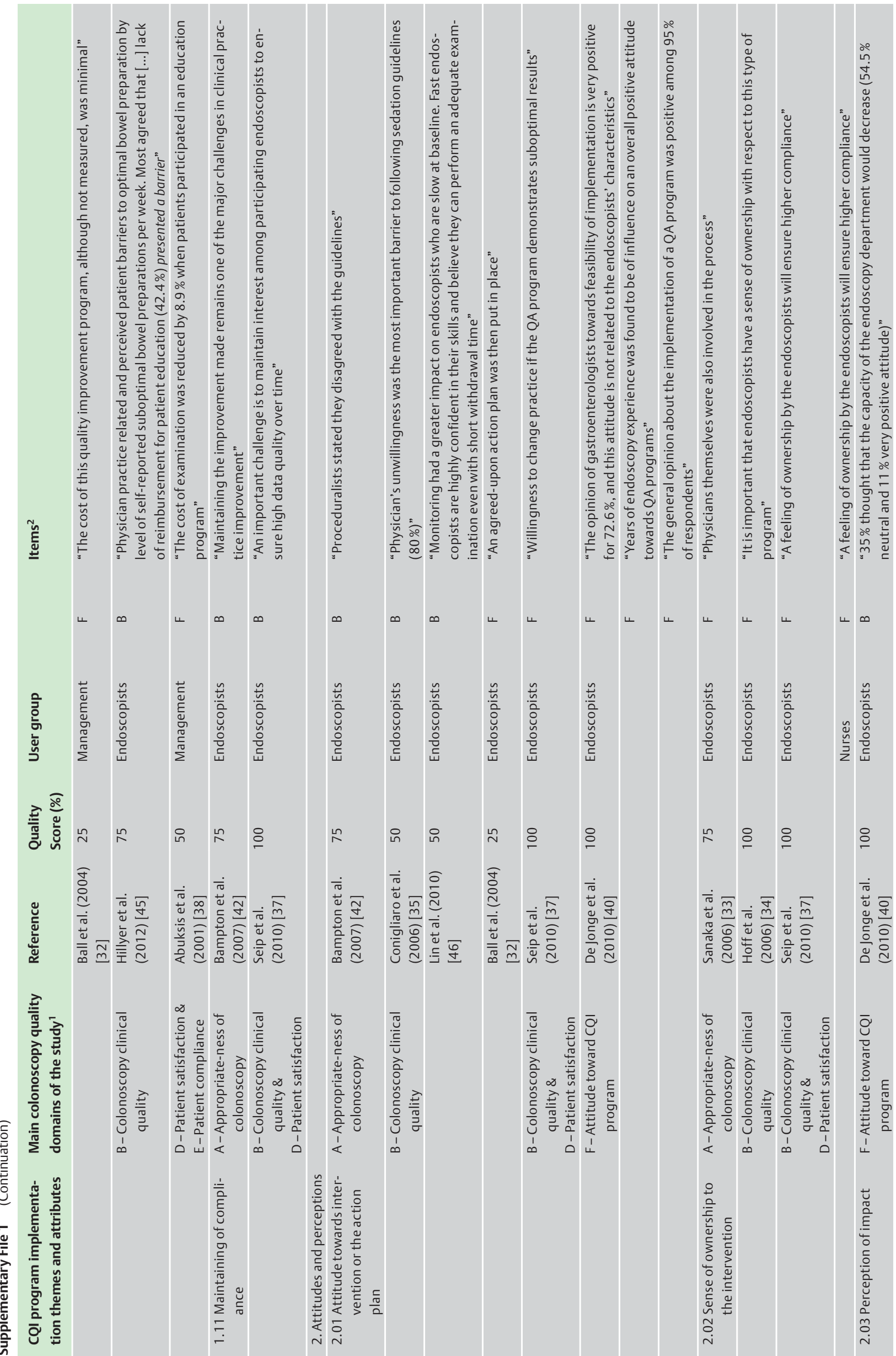




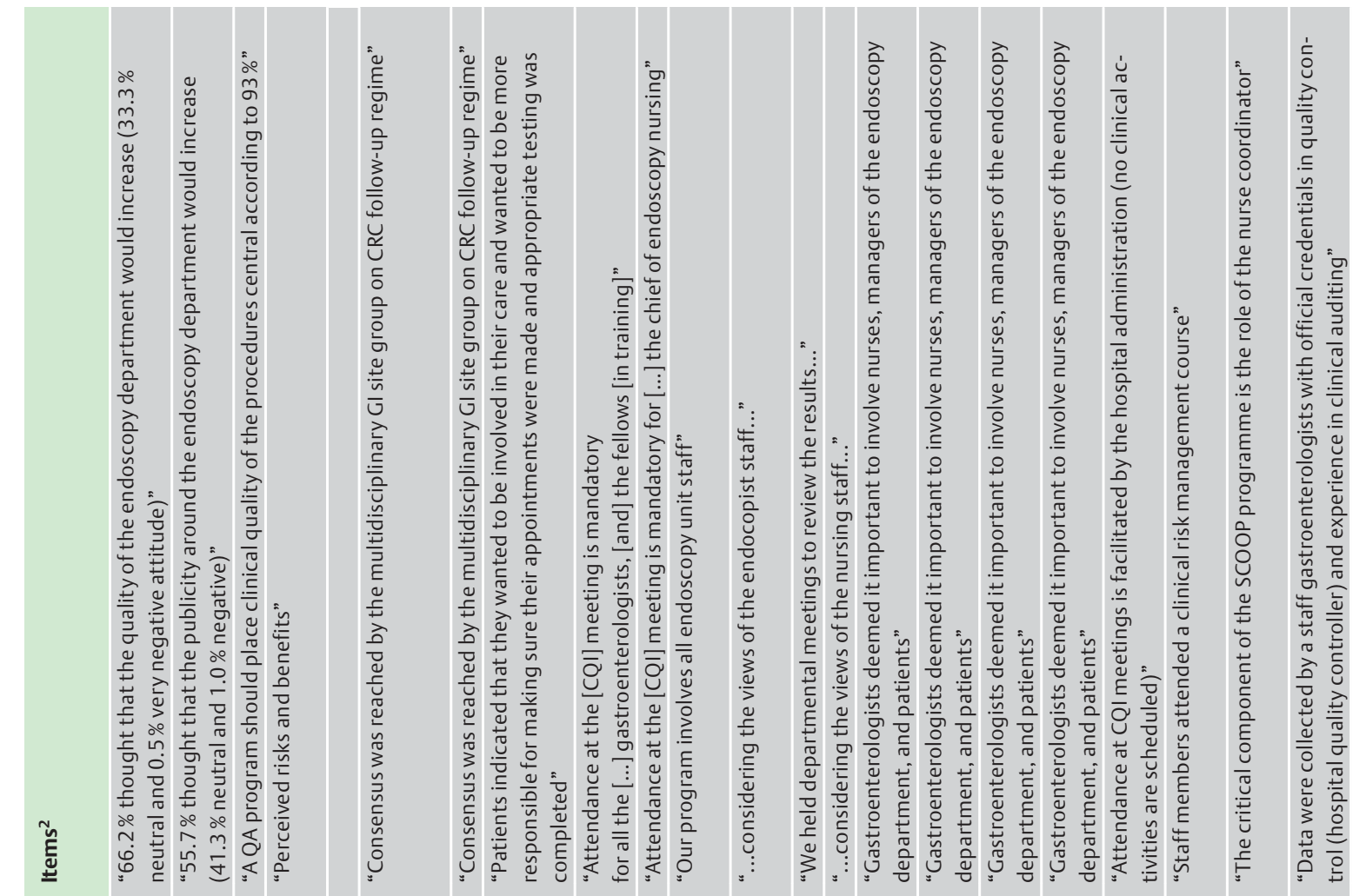

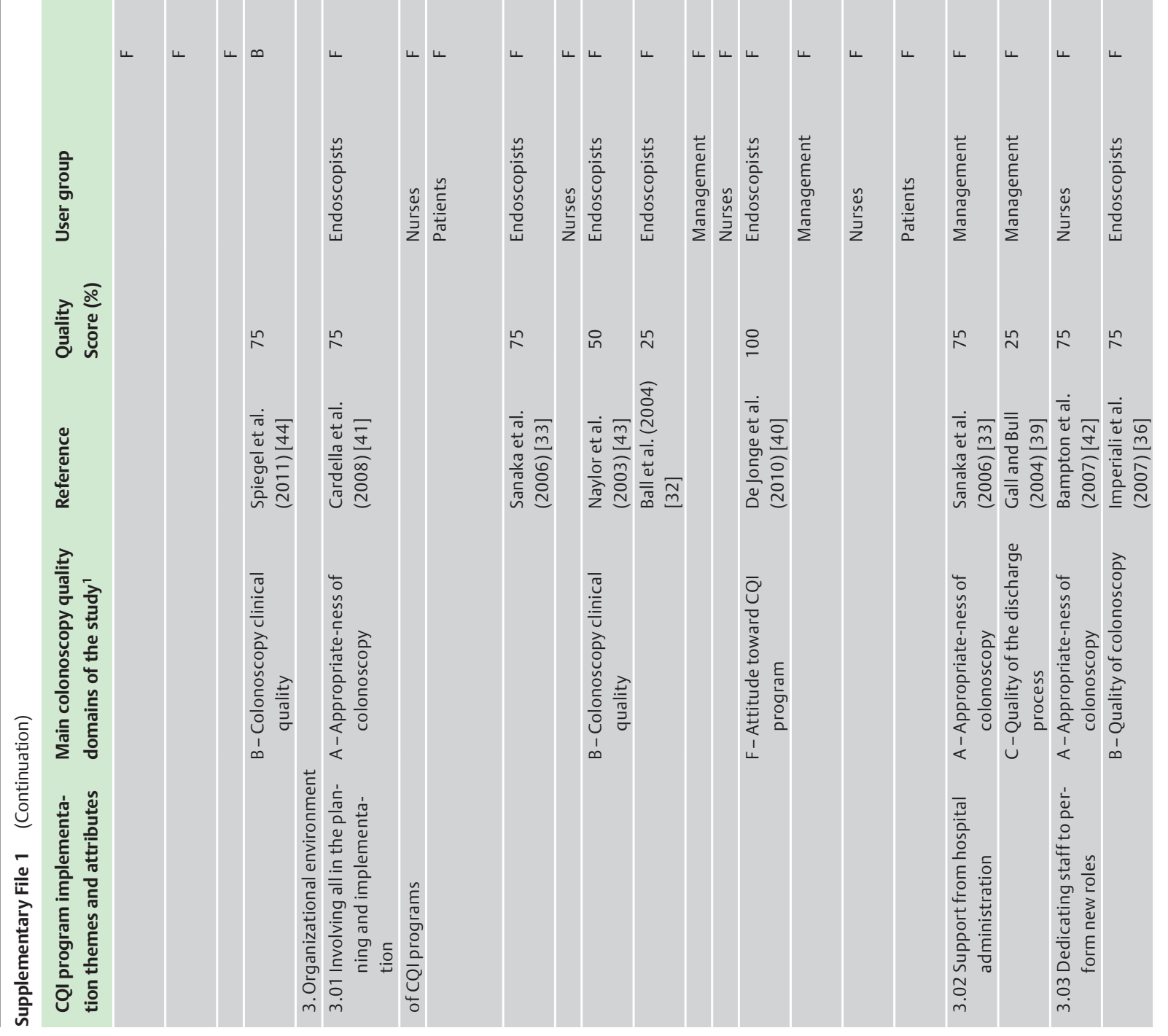




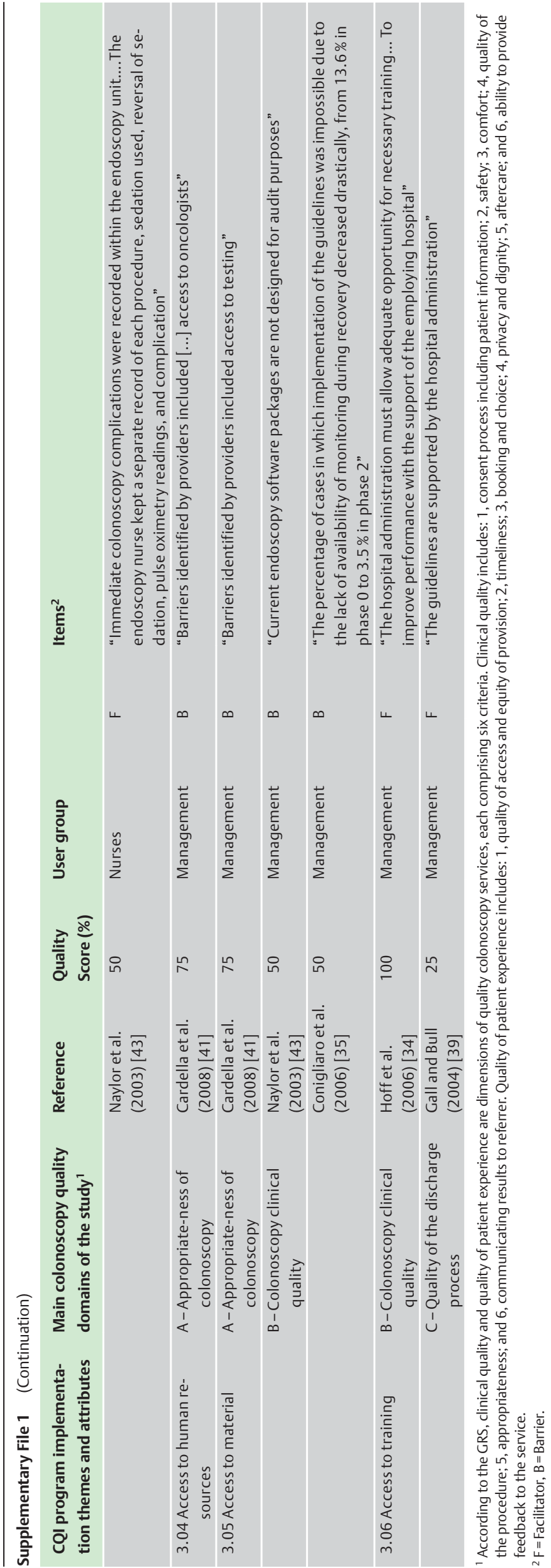

